\title{
Anatomy Education in MBBS: Nepal's Perspective and Challenges
}

\author{
Sandip Shah*, Laxman Khanal and Sarun Koirala \\ Department of Human Anatomy, BPKIHS, Nepal
}

Submission: January 05, 2017; Published: February 20, 2017

*Corresponding author: Dr Sandip Shah, Assistant Professor, Department of Human Anatomy, BPKIHS, Dharan, Nepal, Tel: 977-9842025497; Email: San230dip@yahoo.com

Abstract

Although it is agreed that anatomy is the language of medicine, the 21st century medical curriculum has often shown to reduce the hours dedicated towards anatomy education. Presently TU, Kathmandu University (KU), BP Koirala Institute of Health Sciences (BPKIHS) and Patan Academy of health sciences (PAHS) are running the MBBS program. In designing an anatomy center, the principles of three curricular models may be considered: traditional, integrated problem-based and system-oriented. Anatomy has been given more emphasis in hours of instructions allotted in both institutions. KU has given a total of 472 hours for Anatomy whereas BPKIHS has given 396 hours for the same. It may be noted the teaching of Basic Medical Sciences in an integrated, system wise and with a problem solving approach is the stated objective of all the three curriculums of TU, BPKIHS and KU. It is felt that an efficient clinical anatomy curriculum can only lead to the success in developing an innovative anatomy center for teachers and students. Besides the curricular changes facing anatomy education in recent years, there is also a lack of anatomy teaching faculties in medical college of Nepal.

Keywords: Curriculum; Problem-based; Innovative; Anatomy education; Nepal

Abbreviations: KU: Kathmandu University; BPKIHS: BP Koirala Institute of Health Sciences; PAHS: Patan Academy of health sciences; TU: Tribhuvan University; IOM: Institute of Medicine; SLC: School Leaving Certificate; ISc.: Intermediate Science; AACA: American Association of Clinical Anatomists; MBBS: Bachelor of Medicine and Bachelor of Surgery; PBL: Problem Based Learning, CPC: Clinical Presentation Curriculum; CBLE: Community Based Learning and Education; TOHP: Over-Head Projector and Transparency; PPT: Power Point Presentation

\section{Introduction}

Although it is agreed that anatomy is the language of medicine, the 21 st century medical curriculum has often shown to reduce the hours dedicated towards anatomy education. A medical school therefore should reevaluate its own curriculum what the students need to learn. Since anatomy is exposed to the students at the outset of a curriculum [1], medical schools, therefore, should be careful in planning students-directed anatomy objectives and how they are going to be delivered. This is important as the current pressure to reduce the hours devoted to learning anatomy may even complicate the entire planning $[2,3]$.

Undergraduate anatomy education in medical colleges of Nepal is facing many of the same challenges as in other parts of the world, especially in Problem based learning approach [4,5]. Many claim that PBL curricula dilute basic science education, especially anatomy, with the reason that not all medical graduates will practice surgery [6,7].

\section{Discussion}

\section{History of Medical Schools in Nepal}

The Civil Medical School started in 1934 for training compounders and dressers. Then, during the seventies, Tribhuvan University (TU), Institute of Medicine (IoM) started certificate programs in Nursing, General Medicine, Health Laboratory, Pharmacy, Radiotherapy, Physiotherapy, Health Education and Sanitation for training such assistants. The credit of starting the MBBS program for the first time in the Kingdom of Nepal in 1978 goes to TU. At first, the admission consisted of School Leaving Certificate (SLC) with a Certificate of Medical Sciences of $2 \frac{1}{2}$ or 3 years duration. Afterwards the eligibility became Intermediate Science (ISc.) Higher Secondary Education 
$(10+2)$, A-level or equivalent educational background. Now TU, Kathmandu University (KU), BP Koirala Institute of Health Sciences (BPKIHS) and Patan Academy of health sciences (PAHS) are running the MBBS program. Besides its own School of Medicine, nine other medical colleges are affiliated with KU. Tribhuvan University besides its own IOM has so far given affiliation to seven medical colleges. BPKIHS and PAHS, being a deemed university conducts its own programs only and has not given affiliation, to other institutions [8].

\section{Suggested Content for an Optimal Modern Curriculum}

Curricula on gross anatomy, fertilization, and organogenesis were proposed by the American Association of Clinical Anatomists (AACA) at the turn of the millennium [9]. The initiative to increase learning from a compact course can be categorized in the following sections in addition to the recommended national framework designed by the Education Committee of the Anatomical Society of Great Britain and Ireland (ASGBI): (a) dissection/prosection, (b) multimedia, (c) practical procedures, (d) surface and clinical anatomy, and (e) radiological imaging [10].

\section{Curricula of TU, KU, BPKIHS and PAHS}

In designing an anatomy center, the principles of three curricular models may be considered: traditional, integrated problem-based and system-oriented [11]. The Institute of Medicine (lOM) initiated the Bachelor of Medicine and Bachelor of Surgery (MBBS) course in July 1978. The curriculum was designed in such a way the teaching learning experiencesintegrate basic medical sciences with clinical disciplines. Integrated Basic Medical Science I (General Concepts, Musculoskeletal System, Neurosensory System and special senses); Integrated Basic Medical Science II (Respiratory System, Cardiovascular System, Gastrointestinal and Hepatobilitary System) and Integrated Basic Medical Science III (Renal \& Electrolyte System and Reproductive-Endocrine System).The Degree awarded is Bachelor of Medicine and Bachelor of Surgery, MBBS. MBBS is an undergraduate course. It is a five-and a half year long course which includes one year of internship [12].

The KUMS MBBS program has been divided into three parts: the first two years of study consist of basic medical sciences. These years also include an introduction to clinical sciences. Over the next two and half years, students learn the principles and skills of clinical medicine by rotating through various medical specialties. The final one year consists of an internship [13].

The MBBS curriculum of BPKIHS is thoroughly integrated and community-oriented and partially problem based incorporating the organ system and need based approach. In first two year of MBBS, it consists of Unit 0 (Basic Concepts), Unit 1(Growth, Development and Genetics; Blood and Immunology), Unit 2( Respiratory, Environment including Autonomic Nervous
System and Cardiovascular System), Unit 3 (Gastrointestinal System, Hepatobilitary System, Nutrition and Metabolism), Unit 4 (Endocrine and Reproductive Systems, Kidney and Fluid Balances and Integumentary Systems), Unit 5 (Musculoskeletal System, Nervous system and Special Senses) and Unit 6 ( Multisystem seminars) [14].

Patan Academy of Health Sciences (PAHS) is a public, autonomous, not-for-profit, Health Science University established in 2064 B.S. (2008 A.D.) with the charter granted by the Parliament of Nepal. The total duration of PAHS MBBS curriculum is six years. During the two years long Basic Sciences Course, students is introduced to fundamental concepts about the structure and function of the human body in health and disease as well as the principles of using medicine to treat disease according to organ-systems of the body in an integrated manner rather than disciplinary approach. Among these methods, Problem Based Learning (PBL), Clinical Presentation Curriculum (CPC) with small group sessions, as well as Community Based Learning and Education (CBLE) are the principal teaching learning methods adopted for PAHS MBBS program [15]

It is worthwhile looking at the curriculum of the MBBS courses in Nepal. When BP Koirala Institute of Health Sciences (BPKIHS) and Kathmandu University (KU) curriculum were compared in their Phase I and Part I respectively it was found that 887 hours of theory and 793 hours of practical classes are allotted by BPKIHS whereas 1194 hours of theory classes and 963 hours of practical classes are allotted by KU. Besides KU has allotted 80 hours of other classes for clinical orientation, 30 hours for Medical Informatics and 336 hours for self-study in this curriculum in Part I [12,13,16-17].

\section{Anatomy Education in Nepal}

Anatomy in undergraduate education has been in decline for many years. Some suggest that it has fallen below a safe level. Balances between detail and safety, and assimilation and application of anatomy have yet to be established as the methods of teaching undergo another metamorphosis [18]. The medical curriculum may be said to have evolved during the 20th Century. What had initially been an apprenticeship for professional training for a few years was replaced by a course of study, to enter which the candidate had to be adequately versed in Biology and Chemistry. A medical curriculum makes up the institutional goals, objectives, subject content, learning experiences and assessment techniques [19]. For Nepal though Gray's Textbook of Anatomy was translated into Parbatiya as far back as 1909 it was only in 1978 the first medical course in Nepal was started by the Institute of Medicine [20].

Anatomy has been given more emphasis in hours of instructions allotted in both institutions. KU has given 472 hours for Anatomy whereas BPKIHS has given 396 hours for the same. It may be noted the teaching of Basic Medical Sciences in an integrated, system wise and with a problem solving approach is 
the stated objective of all the three curriculums of TU, BPKIHS and KU. The degree of implementation varies from institution to institution and this is more because of unfamiliarity with the methods rather than opposition by the implementers. Perhaps the reason the NMC has not brought out a printed format of the MBBS curriculum is because the question has been raised at its own meetings whether it is suitable for the NMC to be involved in such details. Members felt that what was being taught was also the responsibility of the universities concerned [20].

The anatomy teaching has also shown some changes as the other part of the world. Anatomy teaching about the content and method has undergone major changes in the recent time constraints, scarcity of cadavers, rapid advances in information technology, and challenges in the demands of the medical profession. Besides, there has been a major pattern shift in medical education from passive, didactic, and teacher-centered approach to active, clinical-based, and student-centered approach [21].

\section{Challenges in Anatomy Education}

It has been shown earlier that simply covering the material within anatomy objectives with didactic lectures followed by dissection may fail to produce a long lasting understanding of the subject. The students are also unable to understand the importance of clinical anatomy integrated within various medical disciplines. However, it is felt that an efficient clinical anatomy curriculum can only lead to the success in developing an innovative anatomy center for teachers and students [22].

In Indian medical colleges, Lectures are still the most common method used for teaching and learning and are here to stay; therefore, it is extremely important that they must be as effective as possible. The most common lecture delivery methods include usage of overhead projector and transparency (TOHP), Power point Presentation (PPT) besides the conventional 'Chalk and talk' method. Various studies have been conducted to compare both methods. The main reasons for liking lectures using chalk and board are: a) the students have adequate time to take down notes and draw diagrams and b) the pauses and breaks during writing and drawing allow the student to follow the material. This Scenario seems to be true in Nepal also [23].

However, there is a continuing debate concerning how much to teach, when to teach, and how to teach gross anatomy. More ever, the planning of best approach to teach anatomy is further complicated by the fact that the time spent for studying anatomy is reduced and on the other and, there is an exponential increase in the wealth of information to be learned [24]. Dissection caters to cognitive, affective, and psychomotor domains of medical students by providing three dimensional perspectives on the topography of the structures but also give opportunity to confirm their learning [25]. Amadio reported that the cadeveric dissection is the only tool that gives the students an appreciation of natural variety of human structures as opposed virtual cadevers [26]. Moore in his work" To dissect or not to dissect" delineated the various disadvantages associated with non-cadever-based curriculum [27].

Some of the chalanges faced in cadaver-based teaching include difficulty in procuring cadevrs, emotional impact on some students on exposure to the cadevrs, and health and safety issues associated with the use of cadevers [28]. Much has been written on PBL in the particular context of learning medicine and anatomy. Overall, about basic science teaching, non-PBL courses seem to be slightly favored, although PBL courses seem to produce more confident, practically-minded doctors [2931]. Recent rapid advances in information and communication technology have changed the pattern of medical education. Computer networks, web based learning, and portable network devices are becoming a fundamental component of the learning environment in medical education, having an impact on design, and reshaping the medical curriculum. Instead of classical textbooks, students now use e-books on laptops or tablet computers. In core courses, such as first year anatomy many medical schools don't use dissection anymore; professionally dissected palastinated specimens and virtual 3D body systems are used instead.

Simulation or imitation using technology of real life circumstances, such as anatomical regions or clinical procedures is useful. For those who must learn or relearn human anatomy without access to cadavers, there's a critical need for learning tools that present images of the real human body in three dimensions. There are two different approaches in the presentation of three-dimensional images: stereoscopic vision and rotation. Stereoscopic vision is used for everyday depth perception, and it's the basis for all 3D images and movies. These visual aids all require special equipment (3D glasses and screens). There is another way - rotation of the object. Object rotation is what we do without thinking, every time we're curious to learn something about a solid object. Many medical apps focus on anatomy and physiology and other subjects, some address medical problem solving, diagnosis, and treatment. Further social media such as Facebook, Twitter and other applications allow students to connect and schedule tutorial sessions, group study sessions and facilitate sharing information and peer-topeer learning [32].

\section{Conclusion}

In addition to the curricular changes facing anatomy education in recent years, there is also lack of anatomy teaching faculties in medical college of Nepal. It now depends on the government of Nepal and universities to unite for promoting the significance of anatomy education and an optimal curriculum before it's decline which can lead to unavoidable results for patient healthcare in Nepalese society. 


\section{Acknowledgment}

The authors would like to thank the central library of B.P Koirala Institute of Health Sciences, Dharan, Nepal for providing access to literature searching for this article. The authors declare that they have no conflict of interests.

\section{References}

1. Collins TJ, Given RL, Hulsebosch CE, Miller BT (1994) Status of gross anatomy in the US and Canada: Dilemma for the 21st century. Clin Anat 7(5): 275-296.

2. Drake RL, Lowrie DJ, Prewitt CM (2002) Survey of gross anatomy, microscopic anatomy, neuroscience, and embryology courses in medical school curricula in the United States. Anat Rec 269(2): 118122.

3. Heylings DJ (2002) Anatomy 1999-2000: the curriculum, who teaches it and how? Med Educ 36(8): 702-310.

4. Monkhouse WS, Farrell TB (1999) Tomorrow's doctors: Today's mistakes? Clin Anat 12(2): 131-134.

5. Hinduja K, Samuel R, Mitchell S (2005) Problem-based learning: Is anatomy a casualty? Surgeon 3(2): 84-87.

6. Parker LM (2002) Anatomical dissection: Why are we cutting it out? Dissection in undergraduate teaching. ANZ J Surg 72(12): 910-912.

7. Gartner LP (2003) Anatomical sciences in the allopathic medical school curriculum in the United States between 1967 and 2001. Clin Anat 16(5): 434-439.

8. Karki DB \& Dixit H (2004) An Overview of Undergraduate and Postgraduate Medical Education in Nepal and Elsewhere. Kathmandu Univ Med J 2(1): 69-74.

9. Leonard RJ, Acland RD, Agur A, Blevins CE, Cahill DR, et al. (1996) A clinical anatomy curriculum for the medical student of the 21st century: Gross anatomy. Clin Anat 9(2): 71-99.

10. McHanwell S, Atkinson M, Davies DC, Dyball R, Morris J, et al. (2007) A core syllabus in anatomy- adding common sense to need to know. Eur J Anat 11(S1): 3-18.

11. Drake RL (1998) Anatomy education in a changing medical curriculum. Anat Rec 253(1): 28-31.

12. Curriculum for MBBS. TU, IoM (1994) Medical Education Dept. IoM, Kathmandu.

13. MBBS Curriculum (2001) Third Version. Basic Medical Sciences, KUPart One.

14. The Second edition of the MBBS Curriculum (2014) BPKIHS, Ghopa, Dharan.
15. Information booklet for MBBS (2014) P. 2-3. Patan academy of health sciences, Nepal.

16. Dixit H (1993) Follow-up on health science students of IoM. Inst Med J 1(15): 222-229.

17. The First Version of the MBBS Curriculum (1996) BPKIHS, Ghopa, Dharan.

18. Turney BW (2007) Anatomy in a modern medical curriculum. Ann R Coll Surg Engl 89(2): 104-107.

19. Jayawickramrajah PT (1991) An enquiry into Medical School Curriculum. Rijksuniversiteit.

20. Dixit H (2003) Role of Nepal Medical Council in MBBS Curriculum. Kathmandu Univ Med J 1(1): 66-71.

21. Singh V, Kharb P (2013) A Paradigm shift from teaching to learning gross anatomy: meta-analysis of implications for instructional methods. Journal of Anatomical Society of India 62(1): 84-89.

22. Ganguly PK (2010) Teaching and Learning of Anatomy in the $21^{\text {st }}$ Century: Direction and the Strategies. The Open Medical Education Journal 3: 5-10.

23. Bartsc RA, Cobern KM (2003) Effectiveness of Power point presentations in lectures. Computer Educ 41(1): 77-86.

24. Seth V, Uphdhaya P, Ahmad M (2010) Impact of Various lectures delivery methods in pharmacology. EXCLIJ 9: 96-101.

25. Pawalina W (2004) Teaching anatomy and changes in the health care system: are anatomists regaining a leadership position? Plexus 4: 6-7.

26. Amadio PC (1996) Reaffirming the importance of dissection. Clin Anat 9(2): 136-137.

27. Moore NA (1998) To dissect or not to dissect? Anat Rec 253(1): 8-9.

28. Cahill KC, Ettarh RR (2009) Attitudes to anatomy dissection in an Irish medical school. Clin Anat 22(3): 386-391.

29. Schmidt HG, Dauphinee WD, Patel VL (1987) Comparing the effects of problem-based and conventional curricula in an international sample. J Med Educ 62(4): 305-315.

30. Vernon DT, Blake RL (1993) Does problem-based learning work?A meta-analysis of evaluative research. Acad Med 68(7): 550-563.

31. Verhoeven BH, Verwijnen GM, Scherpbier AJJA, Holdrinet RSG, Oeseburg B, et al. (1998) An analysis of progress test results of PBL and non-PBL students. Med Teacher 20(4): 310-316.

32. Volodymyr M (2016) Modern Trends in Clinical Anatomy Teaching. MOJ Anatomy \& Physiology 2(1): 00035.
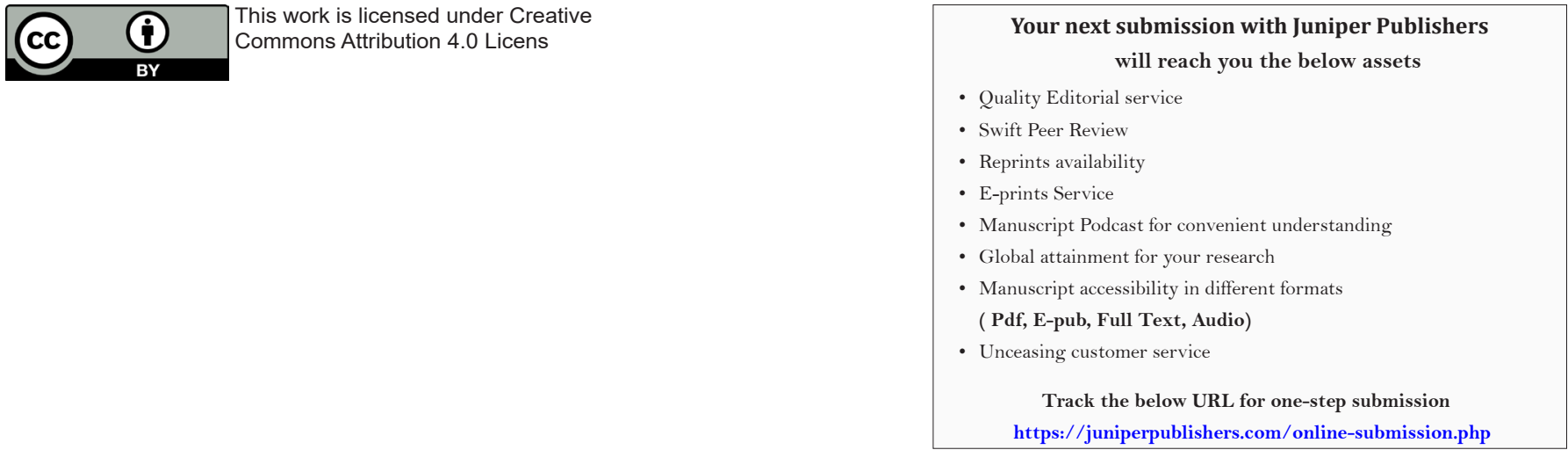